\title{
FAKTOR-FAKTOR PENYEBAB TIMBULNYA WASTE MATERIALS DALAM PELAKSANAAN PROYEK KONSTRUKSI GEDUNG DI KOTA BANDA ACEH
}

\author{
M. Nawawi ${ }^{1)}$, Muttaqin' ${ }^{2)}$, M. Afifuddin ${ }^{3)}$, \\ ${ }^{1,2,3)}$ Magister Teknik Sipil, Universitas Syiah Kuala, Banda Aceh \\ Email: munauwar.nawawi@gmail.com ${ }^{1)}$, muttaqin@unsyiah.ac.id $^{2)}$ \\ m.afifuddin@unsyiah.ac.id ${ }^{3)}$
}

DOI: http://dx.doi.org/10.29103/tj.v11i2.479

(Received: January 2021 / Revised: March 2021 / Accepted: May 2021)

\begin{abstract}
Abstrak
Banyak faktor yang dapat menimbulkan sisa material antara lain faktor desain, pengadaan material, penanganan material, pelaksanaan, residual, dan faktor lain-lain. Penelitian ini bertujuan untuk menganalisis faktor-faktor dan faktor dominan yang menyebabkan timbulnya waste materials dalam pelaksanaan proyek konstruksi gedung di Kota Banda Aceh. Penelitian ini menggunakan pendekatan metode kuantitatif melalui penyebaran kuesioner. Responden ditujukan pada project manager atau site manager dari perusahaan kontraktor bidang gedung di Provinsi Aceh mulai dari kualifikasi Menengah (M1 dan M2) dan kualifikasi Besar (B1 dan B2). Jumlah populasi kontraktor sebanyak 1.610, sedangkan jumlah sampel yang digunakan dalam analisis faktor Principle Component Analysis (PCA) adalah 5 kali dari 35 indikator yang diamati yaitu sebanyak 175 perusahaan. Teknik sampling yang digunakan adalah purposive sampling yaitu pengambilan sampel dengan pertimbangan yang didasarkan pada perusahaan kontraktor yang telah melaksanakan proyek konstruksi bangunan gedung di Provinsi Aceh mulai dari tahun 2010-2019 dengan sumber dana yang berasal dari Anggaran Pendapatan Belanja Daerah (APBD). Analisis data digunakan analisis faktor PCA melalui software Statistical Product and Service Solution (SPSS) versi 26. Hasil penelitian menunjukkan bahwa faktor-faktor yang menyebabkan timbulnya waste materials dalam pelaksanaan proyek konstruksi gedung di Kota Banda Aceh terdapat 6 faktor yaitu faktor desain, pengadaan material, pelaksanaan, spesifikasi dan penanganan material, residual, dan pengontrolan material. Faktor yang dominan menyebabkan timbulnya waste materials dalam pelaksanaan proyek konstruksi gedung di Kota Banda Aceh adalah faktor desain dengan varians sebesar $36,922 \%$.
\end{abstract}

Kata kunci: Material, waste materials, proyek, konstruksi, gedung

\begin{abstract}
Many factors can cause residual material, including design factors, material procurement, material handling, implementation, residuals, and other factors. This study aims to analyze the dominant factors and factors that cause waste materials in the implementation of building construction projects in Banda Aceh City. This study uses a quantitative method approach through distributing questionnaires. Respondents were addressed to the project manager or site manager of a building contractor company in Aceh Province ranging from Medium qualifications (M1 and M2) and Large qualifications (B1 and B2). The total contractor population is 1,610, while the number of samples used in the Principle Component Analysis (PCA) factor analysis is 5 times out of 35 observed indicators, namely 175 companies. The sampling technique used is purposive sampling, which is sampling with consideration based on
\end{abstract}


contracting companies that have implemented building construction projects in Aceh Province starting from 2010-2019 with the source of funds coming from the Regional Budget (APBD. Data analysis used analysis of PCA factors through Statistical Product and Service Solution (SPSS) version 26 software. The results showed that the factors that caused waste materials in the implementation of building construction projects in Banda Aceh City were 6 factors, namely design factors, material procurement, implementation, specification and material handling, residuals, and material control The dominant factor causing the emergence of waste materials in the implementation of building construction projects in Banda Aceh City is the design factor with a variance of $36.922 \%$.

Keywords: Materials, waste materials, projects, construction, buildings

\section{Latar Belakang}

Kota Banda Aceh sebagai pusat pemerintahan Provinsi Aceh, terus berbenah menuju kota hijau (green city) yaitu kota dengan konsep pembangunan kota berkelanjutan yang ramah lingkungan, sehingga kota menjadi tempat yang layak huni tidak hanya bagi generasi sekarang, namun juga untuk generasi mendatang (Bappeda Kota Banda Aceh, 2015). Pembangunan kota berkelanjutan dalam sektor infrastruktur salah satunya dapat ditempuh melalui pembangunan proyek konstruksi gedung. Proyek konstruksi gedung adalah serangkaian kegiatan untuk mendirikan bangunan gedung yang berlangsung dalam tempo waktu terbatas, dengan mengalokasikan sumber daya tertentu. Sumber daya yang perlu dialokasikan oleh perusahaan kontraktor untuk mewujudkan bangunan gedung adalah tenaga kerja, peralatan, dan material. Proyek konstruksi gedung yang ramah lingkungan salah satu indikatornya adalah hasil pembangunan dapat mengurangi sisa material (waste materials).

Waste materials adalah suatu kondisi di mana penggunaan kuantitas material secara boros dari yang diperlukan sehingga dapat menimbulkan sisa material atau limbah pada proyek konstruksi. Dalam pelaksanaannya, waste materials ini terjadi di seluruh proyek konstruksi, oleh karena itu material proyek konstruksi memerlukan pengelolaan yang kompreherensif dan terpadu oleh perusahaan kontraktor, agar waste materials dapat diminimalisir dan waste materials yang timbul dapat ditangani dengan baik. Waste materials dapat diminimalisir dengan meningkatkan pengetahuan dan menaruh perhatian besar oleh pihak perusahaan kontraktor dalam memperlakukan material. Penanganan terhadap waste materials yang timbul dapat dilakukan dengan cara digunakan kembali (reuse), didaur ulang (recycle), dijual (salvage), dan dibuang (disposal) yang sudah tidak mempunyai nilai lagi.

Permasalahan dalam penelitian ini adalah berdasarkan pengamatan proyek konstruksi gedung di Kota Banda Aceh sering kali ditemui adanya waste materials dan yang sering kali ditemui pada proyek seperti semen, agregat halus, agregat kasar, besi tulangan, kayu, triplek, batu bata, cat, keramik, genteng, pipa Poly Vinyl Chloride (PVC), dan material lainnya. Banyak faktor yang dapat menimbulkan sisa material antara lain faktor desain, faktor pengadaan material, faktor penanganan material, faktor pelaksanaan, faktor residual, dan faktor lainlain. Kebanyakan kontraktor yang melaksanakan proyek konstruksi gedung di Kota Banda Aceh kurang menaruh perhatian terhadap faktor-faktor yang dapat menyebabkan timbulnya waste materials. Kurangnya perhatian terhadap waste materials dapat merugikan kontraktor itu sendiri, di mana biaya pelaksanaan 
proyek akan meningkat, sehingga dapat mengurangi profit (keuntungan). Selain itu, kurangnya perhatian terhadap waste materials juga berdampak pada lingkungan, di mana limbah konstruksi dapat menambah kuantitas dari sampah kota yang ketersediaan lahan pembuangan (landfill) semakin lama cenderung berkurang. Penelitian ini bertujuan untuk menganalisis faktor-faktor dan faktor dominan yang menyebabkan timbulnya waste materials dalam pelaksanaan proyek konstruksi gedung di Kota Banda Aceh. Dengan diketahuinya faktorfaktor tersebut, maka perusahaan kontraktor dapat menerapkan manajemen material yang baik, guna untuk menghindari kerugian dan mendukung terwujudnya program green city.

\section{Metode Penelitian}

\subsection{Objek dan Lokasi Penelitian}

Objek dalam penelitian ini adalah proyek konstruksi gedung, yang telah dilaksanakan oleh perusahaan kontraktor bidang gedung mulai dari tahun 20102019, dengan sumber dana yang berasal dari Anggaran Pendapatan Belanja Daerah (APBD). Proyek konstruksi gedung ini mencakup beberapa bangunan yaitu bangunan hunian tunggal dan koppel, bangunan multi atau banyak hunian, bangunan gudang dan industri, bangunan komersial, bangunan hiburan publik, bangunan hotel, restoran, dan bangunan serupa lainnya, bangunan pendidikan, bangunan kesehatan, dan bangunan gedung lainnya. Lokasi proyek konstruksi gedung sebagai lokasi penelitian berada pada wilayah administrasi Kota Banda Aceh.

\subsection{Teknik Penentuan Sampel}

Populasi dimaksudkan kepada perusahaan kontraktor bidang gedung di Provinsi Aceh. Berdasarkan data dari LPJK tahun 2019 jumlah populasi kontraktor bidang gedung yang meliputi kualifikasi Menengah (M1 dan M2) dan kualifikasi Besar (B1 dan B2) diperoleh sebanyak 1.610 perusahaan. Jumlah sampel minimal dalam analisis faktor adalah setidaknya 5 kali dari jumlah indikator yang akan diteliti dan dianalisis (Hair, 2010). Jumlah indikator yang diteliti dan dianalisis dalam penelitian ini adalah sebanyak 35 indikator, oleh karena itu, jumlah sampel dalam penelitian ini adalah 5 x 35 indikator yaitu diperoleh sebanyak 175 perusahaan. Selengkapnya proporsi sampel pada setiap kualifikasi perusahaan kontraktor gedung dapat dilihat pada Tabel 1.

Tabel 1 Proporsi populasi dan sampel pada kualifikasi perusahaan kontraktor

\begin{tabular}{clcc}
\hline No. & \multicolumn{1}{c}{ Sub Kualifikasi } & Populasi & Sampel \\
\hline 1 & Menengah 1 (M1) & 1.407 & $(1.407 / 1.610) \times 175=153$ \\
\hline 2 & Menengah 2 (M2) & 173 & $(173 / 1.610) \times 175=18$ \\
\hline 3 & Besar 1 (B1) & 29 & $(29 / 1.610) \times 175=3$ \\
\hline 4 & Besar 2 (B2) & 1 & $(1 / 1.610) \times 175=1$ \\
\hline & Jumlah & 1.610 & 175 \\
\hline
\end{tabular}

Teknik sampling yang digunakan adalah purposive sampling. Purposive sampling adalah teknik pengambilan sampel ini didasarkan dengan pertimbangan tertentu (Tarjo, 2019). Rentang tahun 2010-2019 ini diambil agar mempunyai lingkup yang luas dalam menemukan 175 perusahaan kontraktor yang 
berpengalaman melaksanakan proyek konstruksi gedung di Kota Banda Aceh untuk disebarkan formulir kuesioner.

\subsection{Teknik Pengumpulan Data}

Kuesioner penelitian dirancang atas dua bagian, yaitu kuesioner bagian A dan kuesioner bagian B. Kuesioner bagian A bertujuan menanyakan tentang karakteristik responden. Indikator karakteristik responden meliputi jenis kelamin, umur, pendidikan terakhir, jabatan perusahaan, kualifikasi perusahaan, dan pengalaman konstruksi gedung. Pengukuran jawaban kuesioner bagian A dilakukan sesuai dengan kepribadian responden. Kuesioner bagian B bertujuan menanyakan tentang faktor-faktor yang menyebabkan timbulnya waste materials dalam pelaksanaan proyek konstruksi gedung di Kota Banda Aceh. Faktor-faktor waste materials yang ditinjau adalah faktor desain, faktor pengadaan material, faktor penanganan material, faktor pelaksanaan, faktor residual, dan faktor lainlain. Indikator dari faktor tersebut dapat dilihat pada Tabel 2.

Tabel 2 Indikator pada faktor-faktor waste materials

\begin{tabular}{|c|c|c|}
\hline No. & Indikator pada Variabel & Kode \\
\hline \multirow[t]{11}{*}{1} & Faktor desain & \\
\hline & a. Kesalahan dalam dokumen kontrak & (Indikator 1) \\
\hline & b. Ketidaklengkapan dokumen kontrak & (Indikator 2) \\
\hline & c. Perubahan desain & (Indikator 3) \\
\hline & d. Memilih spesifikasi produk yang kurang tepat & (Indikator 4) \\
\hline & e. Memilih produk yang berkualitas rendah & (Indikator 5) \\
\hline & f. Kurang memperhatikan ukuran produk yang digunakan & (Indikator 6) \\
\hline & g. Desainer tidak mengenal dengan baik jenis-jenis produk yang lain & (Indikator 7) \\
\hline & h. Pendetailan gambar yang rumit & (Indikator 8) \\
\hline & i. Informasi gambar yang kurang & (Indikator 9) \\
\hline & $\begin{array}{lllll}\text { j. } & \begin{array}{l}\text { Kurang berkoordinasi dengan } \\
\text { berpengetahuan tentang konstruksi }\end{array} & \text { kontraktor } & \text { dan } & \text { kurang } \\
\end{array}$ & (Indikator 10) \\
\hline
\end{tabular}

2 Faktor pengadaan material

a. Kesalahan pemesanan, kelebihan, kekurangan, dan sebagainya $\quad$ (Indikator 11)

b. Pesanan tidak dapat dilakukan dalam jumlah kecil (Indikator 12)

c. Pembelian material yang tidak sesuai dengan spesifikasi (Indikator 13)

d. Pemasok mengirim barang tidak sesuai dengan spesifikasi (Indikator 14)

e. Kemasan buruk, menyebabkan terjadi kerusakan dalam perjalanan (Indikator 15)

3 Faktor penanganan material

a. Material yang terkirim dalam keadaan tidak padat atau kurang (Indikator 16)

b. Membuang atau melempar material (Indikator 17)

c. Penanganan material yang tidak hati-hati pada saat pembongkaran (Indikator 18) untuk dimasukkan ke dalam gudang

d. Penyimpanan material yang tidak benar menyebabkan kerusakan (Indikator 19)

4 Faktor pelaksanaan

a. Kesalahan yang diakibatkan oleh tenaga kerja (Indikator 20)

b. Peralatan yang tidak berfungsi dengan baik (Indikator 21)

c. Cuaca yang buruk (Indikator 22)

d. Kecelakaan pekerja di lapangan (Indikator 23)

e. Penggunaan material yang salah sehingga perlu diganti $\quad$ (Indikator 24)

f. Metode untuk menempatkan pondasi (Indikator 25)

Faktor-Faktor Penyebab Timbulnya Waste Materials Dalam Pelaksanaan Proyek

Konstruksi Gedung Di Kota Banda Aceh - M. Nawawi, Muttaqin, M. Afifuddin 


\begin{tabular}{|c|c|}
\hline & $\begin{array}{l}\text { g. Jumlah material yang dibutuhkan tidak diketahui karena (Indikator 26) } \\
\text { perencanaan tidak sempurna }\end{array}$ \\
\hline & $\begin{array}{l}\text { h. Informasi tipe dan ukuran material yang akan digunakan terlambat (Indikator 27) } \\
\text { disampaikan kepada kontraktor }\end{array}$ \\
\hline & $\begin{array}{l}\text { i. Kecerobohan dalam mencampur, mengolah, dan kesalahan dalam (Indikator 28) } \\
\text { penggunaan material sehingga perlu diganti }\end{array}$ \\
\hline & $\begin{array}{l}\text { j. Pengukuran di lapangan tidak akurat sehingga terjadi kelebihan (Indikator 29) } \\
\text { volume }\end{array}$ \\
\hline 5 & sidual \\
\hline & otongan material tidak dapat dipakai lagi \\
\hline & b. Kesalah \\
\hline & c. Kesalahan pesanan barang, karena tidak menguasai spesifikasi \\
\hline & d. Sisa material karena proses pemakaian \\
\hline 6 & Faktor lain-lain \\
\hline & a. Kehilangan akibat pencurian \\
\hline & $\begin{array}{l}\text { b. Buruknya pengontrolan material di proyek dan perencanaan (Indikator 35) } \\
\text { manajemen terhadap sisa material }\end{array}$ \\
\hline
\end{tabular}

Pengukuran jawaban kuesioner bagian B menggunakan skala Likert. Pengumpulan data kuesioner dilakukan dengan menjumpai langsung tempat keberadaan responden dan memberikan formulir kuesioner. Mengingat banyaknya jumlah kuesioner yang harus dibagi, maka dalam proses pembagian kuesioner kepada perusahaan kontraktor dibantu oleh beberapa rekan peneliti. Pembagian kuesioner dilakukan pendampingan, agar bila terdapat pertanyaan yang sulit dimengerti oleh responden dapat diberikan penjelasan. Kriteria pengisi kuesioner adalah project manager atau site manager. Pengumpulan data kuesioner dilakukan dalam rentang waktu 1 bulan.

\subsection{Teknik Analisis Data}

Analisis data ini menggunakan Principle Component Analysis (PCA). PCA adalah untuk mengurangi dimensi kumpulan data yang terdiri dari sejumlah besar variabel yang saling terkait, sambil mempertahankan sebanyak mungkin variasi yang ada dalam kumpulan data, hal ini dicapai dengan mentransformasikan ke sekumpulan variabel baru. Komponen utama yang tidak berkorelasi diurutkan sehingga beberapa variabel pertama mempertahankan sebagian besar variasi yang ada di semua variabel asli (Jolliffe, 2013). PCA ini digunakan untuk mengevaluasi faktor-faktor yang menyebabkan timbulnya waste materials dalam pelaksanaan proyek konstruksi gedung yang diambil dari sebuah sumber, untuk selanjutnya dicari tau apakah faktor-faktor tersebut muncul pada wilayah Kota Banda Aceh. Faktor-faktor waste materials yang dievaluasi adalah faktor desain, pengadaan material, penanganan material, pelaksanaan, residual, dan faktor lain-lain. Langkah-langkah analisis faktor PCA melalui software SPSS versi 26 dapat diuraikan sebagai berikut:

1. Melakukan korelasi matrik

Korelasi matrik ini bertujuan untuk memeriksa seluruh indikator yang diambil dari suatu sumber dapat dibentuk menjadi suatu faktor atau tidak, untuk memastikan jumlah sampel yang ditetapkan sudah memadai atau tidak untuk diterapkan PCA, dan untuk menyeleksi sejumlah indikator yang diambil dari 
suatu sumber dapat muncul di wilayah penelitian atau tidak. Syarat parameter korelasi matrik adalah sebagai berikut:

a. Bila nilai Kaiser Meyer Olkin (KMO)>0,5, maka seluruh indikator yang diambil dari suatu sumber dapat dibentuk menjadi suatu faktor. Sebaliknya bila nilai $\mathrm{KMO}<0,5$, maka seluruh indikator yang diambil dari suatu sumber tidak dapat dibentuk menjadi suatu faktor.

b. Bila nilai Sig $<0,05$, maka jumlah sampel yang ditetapkan sebanyak 175 responden sudah memadai untuk diterapkan PCA. Sebaliknya bila nilai KMO >0,05, maka jumlah sampel yang ditetapkan sebanyak 175 responden belum memadai untuk diterapkan PCA. Tindak lanjut bila nilai Sig $>0,05$ adalah dengan menggunakan rumus sampel maksimal yaitu 10 dikali jumlah indikator.

c. Bila indikator mempunyai nilai MSA $>0,5$, maka indikator yang diambil dari suatu sumber muncul di wilayah penelitian. Sebaliknya bilai nilai MSA $<0,5$, maka sejumlah indikator yang diambil dari suatu sumber tidak muncul di wilayah penelitian. Tindak lanjut bila sejumlah indikator mempunyai nilai MSA $<0,5$ adalah melakukan percobaan selanjutnya dengan mengeluarkan indikator yang mempunyai nilai MSA terkecil.

2. Melakukan ekstraksi faktor

Ekstraksi faktor ini bertujuan untuk mengetahui jumlah faktor yang terbentuk, untuk mengetahui keberadaan faktor dominan, dan untuk mengetahui kontribusi sejumlah faktor yang terbentuk. Syarat parameter ekstraksi faktor adalah sebagai berikut:

a. Bila nilai eigen $>1$ berhenti pada kedudukan komponen atau indikator tertentu, maka jumlah faktor yang bisa terbentuk sesuai dengan kedudukan komponen.

b. Nilai varians tertinggi pada suatu komponen menandakan komponen tersebut adalah faktor dominan.

c. Nilai kumulatif terakhir menandakan kontribusi sejumlah faktor yang terbentuk yang dinyatakan dalam bentuk persentase.

3. Melakukan rotasi faktor

Rotasi faktor ini bertujuan untuk mendistribusikan sejumlah indikator pada kelompok faktor yang terbentuk. Alternatif yang digunakan dalam rotasi faktor adalah orthogonal rotation, yaitu proses rotasi memutar sumbu $90^{\circ}$ dengan metode varimax. Syarat parameter rotasi faktor adalah indikator yang mempunyai nilai loading factor tertinggi pada suatu faktor akan dimasukkan pada faktor tersebut.

4. Memberikan nama faktor

Setelah beberapa faktor terbentuk, maka proses dilanjutkan dengan menamakan faktor. Dalam penamaan faktor harus memperhatikan seluruh indikator yang ada, agar indikator tersebut representatif atau mencerminkan faktor yang hendak diberi nama.

\section{Hasil dan Pembahasan}

\subsection{Korelasi Matrik}

Tahap korelasi matrik dalam PCA ini mempunyai 3 tujuan utama. Tujuan pertama untuk memeriksa seluruh indikator yang diambil dari suatu sumber dapat dibentuk menjadi suatu faktor atau tidak, dengan syarat KMO $>0,5$. Tujuan kedua 
untuk memastikan jumlah sampel yang ditetapkan sudah memadai atau tidak untuk diterapkan PCA, dengan syarat nilai $\mathrm{Sig}<0,05$. Tujuan ketiga untuk menyeleksi seluruh indikator yang diambil dari suatu sumber dapat muncul di wilayah penelitian atau tidak, dengan syarat MSA $>0,5$. Adapun output korelasi matrik ini diperlihatkan pada Tabel 3.

Tabel 3 Korelasi matrik

\begin{tabular}{|c|c|c|c|c|c|c|c|c|c|}
\hline \multirow{2}{*}{ Parameter } & \multicolumn{9}{|c|}{ Percobaan Korelasi Matrik } \\
\hline & 1 & 2 & 3 & 4 & 5 & 6 & 7 & 8 & 9 \\
\hline $\mathrm{KMO} \geq 0,5$ & 0,477 & 0,578 & 0,616 & 0,635 & 0,657 & 0,666 & 0,669 & 0,673 & 0,688 \\
\hline Sig. $<0,05$ & 0,000 & 0,000 & 0,000 & 0,000 & 0,000 & 0,000 & 0,000 & 0,000 & 0,000 \\
\hline MSA $<0,5$ & 21 & 8 & 4 & 3 & 2 & 2 & 1 & 1 & - \\
\hline Indikator 1 & $\mathbf{0 , 4 3 0}$ & $\mathbf{0 , 3 4 7}$ & 0,546 & 0,525 & 0,480 & 0,470 & - & - & - \\
\hline Indikator 2 & $\mathbf{0 , 3 2 2}$ & 0,374 & 0,566 & 0,527 & 0,567 & 0,473 & 0,446 & - & - \\
\hline Indikator 3 & 0,492 & 0,651 & 0,608 & 0,623 & 0,591 & 0,560 & 0,553 & 0,526 & 0,539 \\
\hline Indikator 4 & 0,631 & 0,632 & 0,689 & 0,690 & 0,788 & 0,835 & 0,840 & 0,846 & 0,836 \\
\hline Indikator 5 & 0,374 & 0,466 & 0,607 & 0,623 & 0,580 & 0,675 & 0,657 & 0,673 & 0,668 \\
\hline Indikator 6 & 0,654 & 0,575 & 0,551 & 0,648 & 0,618 & 0,618 & 0,656 & 0,651 & 0,631 \\
\hline Indikator 7 & 0,456 & 0,548 & 0,520 & 0,578 & 0,552 & 0,523 & 0,512 & 0,510 & 0,505 \\
\hline Indikator 8 & 0,684 & 0,712 & 0,678 & 0,662 & 0,631 & 0,766 & 0,759 & 0,759 & 0,771 \\
\hline Indikator 9 & $\mathbf{0 , 3 7 8}$ & 0,662 & 0,701 & 0,653 & 0,652 & 0,637 & 0,629 & 0,613 & 0,708 \\
\hline Indikator 10 & $\mathbf{0 , 3 8 7}$ & 0,392 & 0,386 & 0,367 & - & - & - & - & - \\
\hline Indikator 11 & 0,594 & 0,548 & 0,641 & 0,646 & 0,675 & 0,764 & 0,751 & 0,749 & 0,820 \\
\hline Indikator 12 & 0,405 & 0,652 & 0,641 & 0,638 & 0,746 & 0,736 & 0,735 & 0,725 & 0,717 \\
\hline Indikator 13 & 0,440 & 0,643 & 0,673 & 0,719 & 0,695 & 0,694 & 0,694 & 0,673 & 0,657 \\
\hline Indikator 14 & 0,432 & 0,405 & 0,552 & 0,543 & 0,559 & 0,595 & 0,604 & 0,667 & 0,727 \\
\hline Indikator 15 & 0,610 & 0,581 & 0,653 & 0,647 & 0,701 & 0,678 & 0,665 & 0,670 & 0,674 \\
\hline Indikator 16 & 0,674 & 0,660 & 0,743 & 0,796 & 0,791 & 0,781 & 0,764 & 0,774 & 0,828 \\
\hline Indikator 17 & 0,541 & 0,525 & 0,564 & 0,538 & 0,588 & 0,600 & 0,601 & 0,613 & 0,635 \\
\hline Indikator 18 & 0,751 & 0,715 & 0,673 & 0,744 & 0,745 & 0,730 & 0,753 & 0,763 & 0,750 \\
\hline Indikator 19 & $\mathbf{0 , 3 6 3}$ & 0,645 & 0,610 & 0,678 & 0,659 & 0,675 & 0,691 & 0,676 & 0,660 \\
\hline Indikator 20 & 0,673 & 0,702 & 0,691 & 0,705 & 0,667 & 0,665 & 0,648 & 0,647 & 0,628 \\
\hline Indikator 21 & 0,221 & 0,287 & - & - & - & - & - & - & - \\
\hline Indikator 22 & 0,622 & 0,572 & 0,544 & 0,525 & 0,657 & 0,648 & 0,657 & 0,652 & 0,674 \\
\hline Indikator 23 & $\mathbf{0 , 3 3 7}$ & 0,529 & 0,457 & 0,469 & 0,444 & - & - & - & - \\
\hline Indikator 24 & 0,745 & 0,702 & 0,689 & 0,746 & 0,698 & 0,689 & 0,692 & 0,660 & 0,662 \\
\hline Indikator 25 & $\mathbf{0 , 2 2 0}$ & - & - & - & - & - & - & - & - \\
\hline Indikator 26 & 0,717 & 0,643 & 0,676 & 0,739 & 0,738 & 0,709 & 0,719 & 0,787 & 0,792 \\
\hline Indikator 27 & 0,659 & 0,614 & 0,613 & 0,589 & 0,586 & 0,550 & 0,538 & 0,485 & - \\
\hline Indikator 28 & $\mathbf{0 , 4 9 8}$ & 0,571 & 0,517 & 0,531 & 0,592 & 0,576 & 0,559 & 0,559 & 0,539 \\
\hline Indikator 29 & 0,582 & 0,717 & 0,686 & 0,708 & 0,729 & 0,741 & 0,748 & 0,736 & 0,762 \\
\hline Indikator 30 & 0,419 & 0,565 & 0,625 & 0,621 & 0,692 & 0,654 & 0,655 & 0,656 & 0,692 \\
\hline Indikator 31 & 0,352 & 0,500 & 0,475 & 0,459 & 0,534 & 0,598 & 0,586 & 0,606 & 0,642 \\
\hline Indikator 32 & 0,479 & 0,740 & 0,829 & 0,807 & 0,793 & 0,775 & 0,816 & 0,802 & 0,789 \\
\hline Indikator 33 & $\mathbf{0 , 2 7 1}$ & 0,648 & 0,621 & 0,602 & 0,580 & 0,569 & 0,545 & 0,579 & 0,596 \\
\hline Indikator 34 & $\mathbf{0 , 2 9 9}$ & $\mathbf{0 , 3 1 1}$ & 0,294 & - & - & - & - & - & - \\
\hline Indikator 35 & 0,240 & $\mathbf{0 , 4 5 2}$ & 0,564 & 0,575 & 0,569 & 0,534 & 0,541 & 0,524 & 0,529 \\
\hline
\end{tabular}

Tabel 3 memperlihatkan bahwa korelasi matrik telah dilakukan beberapa kali hingga percobaan 9. Percobaan tersebut dilakukan untuk memenuhi seluruh syarat parameter pada korelasi matrik. 


\subsection{Ekstraksi Faktor}

Tahap ekstraksi faktor dalam PCA ini mempunyai 3 tujuan utama. Tujuan pertama untuk mengetahui jumlah faktor yang terbentuk dengan menghitung jumlah komponen atau indikator yang mempunyai nilai eigen $>1$. Tujuan kedua untuk mengetahui faktor dominan dengan melihat nilai varians tertinggi pada salah satu faktor. Tujuan ketiga untuk mengetahui kontribusi sejumlah faktor yang terbentuk dengan melihat nilai kumulatif varians. Adapun output ekstraksi faktor ini diperlihatkan pada Tabel 4.

Tabel 4 Ekstraksi faktor

\begin{tabular}{|c|c|c|c|c|c|c|}
\hline \multirow{2}{*}{$\begin{array}{l}\text { Komponen/ } \\
\text { Indikator }\end{array}$} & \multicolumn{3}{|c|}{ Nilai Eigen } & \multicolumn{3}{|c|}{ Ekstraksi Faktor } \\
\hline & Total & Varians $(\%)$ & Kumulatif $(\%)$ & Total & Varians (\%) & Kumulatif (\%) \\
\hline 1 & 9,969 & 36,922 & 36,922 & 9,969 & 36,922 & 36,922 \\
\hline 2 & 3,674 & 13,609 & 50,531 & 3,674 & 13,609 & 50,531 \\
\hline 3 & 2,049 & 7,588 & 58,119 & 2,049 & 7,588 & 58,119 \\
\hline 4 & 1,880 & 6,964 & 65,083 & 1,880 & 6,964 & 65,083 \\
\hline 5 & 1,417 & 5,247 & 70,330 & 1,417 & 5,247 & 70,330 \\
\hline 6 & 1,171 & 4,336 & 74,666 & 1,171 & 4,336 & 74,666 \\
\hline 7 & 0,969 & 3,590 & 78,256 & & & \\
\hline 8 & 0,942 & 3,489 & 81,745 & & & \\
\hline 9 & 0,692 & 2,564 & 84,309 & & & \\
\hline 10 & 0,610 & 2,259 & 86,568 & & & \\
\hline 11 & 0,554 & 2,054 & 88,622 & & & \\
\hline 12 & 0,459 & 1,699 & 90,321 & & & \\
\hline 13 & 0,406 & 1,502 & 91,823 & & & \\
\hline 14 & 0,361 & 1,337 & 93,160 & & & \\
\hline 15 & 0,292 & 1,080 & 94,241 & & & \\
\hline 16 & 0,268 & 0,991 & 95,232 & & & \\
\hline 17 & 0,243 & 0,901 & 96,133 & & & \\
\hline 18 & 0,202 & 0,750 & 96,883 & & & \\
\hline 19 & 0,182 & 0,673 & 97,556 & & & \\
\hline 20 & 0,166 & 0,616 & 98,172 & & & \\
\hline 21 & 0,125 & 0,461 & 98,633 & & & \\
\hline 22 & 0,116 & 0,430 & 99,063 & & & \\
\hline 23 & 0,081 & 0,301 & 99,364 & & & \\
\hline 24 & 0,067 & 0,248 & 99,612 & & & \\
\hline 25 & 0,049 & 0,183 & 99,795 & & & \\
\hline 26 & 0,036 & 0,132 & 99,926 & & & \\
\hline 27 & 0,020 & 0,074 & 100,000 & & & \\
\hline
\end{tabular}

Tabel 4 memperlihatkan bahwa nilai eigen>1 terletak pada komponen 1 hingga 6, hal ini berarti bahwa jumlah faktor yang terbentuk ada 6 faktor dari 27 indikator yang muncul di wilayah penelitian. Nilai variance tertinggi terletak pada komponen 1 sebesar $36,922 \%$, hal ini berarti bahwa faktor dominan terletak pada faktor 1 sebesar 36,922\%. Nilai kumulatif varians diperoleh sebesar 74,666\%, hal ini berarti bahwa kontribusi 6 faktor yang terbentuk adalah sebesar 74,666\%.

\subsection{Rotasi Faktor}

Tahap rotasi faktor dalam PCA ini bertujuan untuk mendistribusikan sejumlah indikator yang muncul di wilayah penelitian pada kelompok faktor yang terbentuk dengan melihat loading factor tertinggi. Alternatif yang digunakan 
dalam rotasi faktor adalah orthogonal rotation, yaitu proses rotasi memutar sumbu $90^{\circ}$ dengan metode varimax. Melalui metode tersebut loading factor yang awalnya kecil akan semakin diperkecil dan loading factor yang besar semakin diperbesar. Oleh karena itu pada komponen faktor, tidak akan ditemukan lagi peluang indikator dengan nilai loading factor yang sama-sama besar. Adapun output rotasi faktor ini diperlihatkan pada Tabel 5.

Tabel 5 Rotasi faktor

\begin{tabular}{|c|c|c|c|c|c|c|}
\hline & \multicolumn{6}{|c|}{ Faktor } \\
\hline & 1 & 2 & 3 & 4 & 5 & 6 \\
\hline Indikator 3 & 0,774 & 0,166 & $-0,024$ & $-0,052$ & $-0,014$ & 0,073 \\
\hline Indikator 4 & 0,116 & 0,377 & 0,449 & 0,476 & 0,009 & $-0,251$ \\
\hline Indikator 5 & 0,128 & 0,116 & 0,093 & 0,869 & $-0,247$ & 0,083 \\
\hline Indikator 6 & 0,099 & 0,250 & 0,268 & 0,672 & 0,346 & $-0,292$ \\
\hline Indikator 7 & 0,719 & 0,040 & 0,132 & 0,070 & $-0,063$ & 0,361 \\
\hline Indikator 8 & $\mathbf{0 , 8 0 7}$ & 0,217 & 0,256 & $-0,071$ & $-0,077$ & $-0,067$ \\
\hline Indikator 9 & 0,845 & $-0,031$ & $-0,103$ & 0,258 & 0,158 & 0,014 \\
\hline Indikator 11 & 0,504 & 0,505 & 0,325 & 0,121 & 0,138 & 0,185 \\
\hline Indikator 12 & 0,100 & 0,646 & 0,288 & 0,065 & 0,367 & $-0,154$ \\
\hline Indikator 13 & 0,147 & 0,695 & 0,370 & 0,283 & $-0,110$ & $-0,335$ \\
\hline Indikator 14 & 0,043 & 0,708 & $-0,015$ & 0,318 & $-0,083$ & 0,201 \\
\hline Indikator 15 & 0,220 & 0,724 & 0,387 & 0,096 & 0,050 & $-0,162$ \\
\hline Indikator 16 & 0,312 & 0,600 & 0,112 & 0,427 & 0,072 & 0,136 \\
\hline Indikator 17 & 0,129 & 0,202 & 0,548 & 0,287 & 0,531 & 0,131 \\
\hline Indikator 18 & 0,185 & 0,381 & 0,368 & 0,597 & 0,318 & 0,247 \\
\hline Indikator 19 & $-0,237$ & 0,336 & 0,346 & 0,538 & 0,162 & 0,361 \\
\hline Indikator 20 & $-0,003$ & 0,359 & 0,789 & 0,120 & 0,169 & 0,167 \\
\hline Indikator 22 & 0,326 & 0,020 & 0,755 & 0,333 & $-0,254$ & $-0,128$ \\
\hline Indikator 24 & $-0,076$ & 0,211 & 0,673 & 0,484 & 0,061 & 0,073 \\
\hline Indikator 26 & 0,804 & 0,231 & $-0,044$ & 0,100 & 0,160 & 0,092 \\
\hline Indikator 28 & $-0,018$ & 0,275 & 0,794 & 0,005 & $-0,122$ & 0,099 \\
\hline Indikator 29 & 0,404 & 0,175 & 0,112 & 0,503 & 0,046 & $\mathbf{0 , 5 8 8}$ \\
\hline Indikator 30 & $-0,169$ & 0,386 & 0,353 & 0,452 & 0,479 & 0,084 \\
\hline Indikator 31 & 0,141 & 0,341 & 0,297 & 0,175 & $-0,677$ & 0,198 \\
\hline Indikator 32 & 0,360 & 0,713 & 0,335 & 0,065 & 0,006 & 0,028 \\
\hline Indikator 33 & 0,373 & 0,156 & $-0,046$ & 0,026 & 0,621 & 0,162 \\
\hline Indikator 35 & 0,260 & $-0,114$ & 0,095 & $-0,010$ & 0,020 & 0,844 \\
\hline Jumlah indikator & 5 & 7 & 5 & 5 & 3 & 2 \\
\hline
\end{tabular}

Tabel 5 memperlihatkan bahwa setiap indikator mempunyai loading factor tertinggi pada masing-masing faktor. Dalam hal ini faktor 1 terdistribusi 5 indikator, faktor 2 terdistribusi 7 indikator, faktor 3 terdistribusi 5 indikator, faktor 4 terdistribusi 5 indikator, faktor 5 terdistribusi 3 indikator, dan faktor 6 terdistribusi 2 indikator.

\subsection{Pemberian Nama Faktor}

Tahap pemberian nama faktor bertujuan untuk melekatkan nama faktor berdasarkan kecenderungan karakteristik indikator yang berkumpul dalam faktor yang terbentuk. Pemberian nama faktor ini lebih bersifat subjektif, yang diupayakan representatif terhadap sejumlah indikator yang berkumpul dalam suatu faktor. Pemberian nama untuk setiap faktor yang terbentuk dapat diuraikan berikut ini: 


\section{Faktor 1}

Faktor 1 terdiri dari 5 indikator yaitu sebagai berikut:

a. Indikator 3 (perubahan desain).

b. Indikator 7 (desainer tidak mengenal dengan baik jenis-jenis produk yang lain).

c. Indikator 8 (pendetailan gambar yang rumit).

d. Indikator 9 (informasi gambar yang kurang).

e. Indikator 26 (jumlah material yang dibutuhkan tidak diketahui karena perencanaan tidak sempurna).

Berdasarkan indikator di atas, maka faktor 1 ini dapat diberi nama sebagai faktor desain.

2. Faktor 2

Faktor 2 terdiri dari 7 indikator yaitu sebagai berikut:

a. Indikator 11 (kesalahan pemesanan, kelebihan, kekurangan, dan sebagainya).

b. Indikator 12 (pesanan tidak dapat dilakukan dalam jumlah kecil).

c. Indikator 13 (pembelian material yang tidak sesuai dengan spesifikasi).

d. Indikator 14 (pemasok mengirim barang tidak sesuai dengan spesifikasi).

e. Indikator 15 (kemasan buruk, menyebabkan terjadi kerusakan dalam perjalanan).

f. Indikator 16 (material yang terkirim dalam keadaan tidak padat atau kurang).

g. Indikator 32 (kesalahan pesanan barang, karena tidak menguasai spesifikasi).

Berdasarkan indikator di atas, maka faktor 2 ini dapat diberi nama sebagai faktor pengadaan material.

4. Faktor 3

Faktor 3 terdiri dari 5 indikator yaitu sebagai berikut:

a. Indikator 17 (membuang atau melempar material).

b. Indikator 20 (kesalahan yang diakibatkan oleh tenaga kerja).

c. Indikator 22 (cuaca yang buruk).

d. Indikator 24 (penggunaan material yang salah sehingga perlu diganti).

e. Indikator 28 (kecerobohan dalam mencampur, mengolah, dan kesalahan dalam penggunaan material sehingga perlu diganti).

Berdasarkan indikator di atas, maka faktor 3 ini dapat diberi nama sebagai faktor pelaksanaan.

5. Faktor 4

Faktor 4 terdiri dari 5 indikator yaitu sebagai berikut:

a. Indikator 4 (memilih spesifikasi produk yang kurang tepat).

b. Indikator 5 (memilih produk yang berkualitas rendah).

c. Indikator 6 (kurang memperhatikan ukuran produk yang digunakan).

d. Indikator 18 (penanganan material yang tidak hati-hati pada saat pembongkaran untuk dimasukkan ke dalam gudang).

e. Indikator 19 (penyimpanan material yang tidak benar menyebabkan kerusakan).

Berdasarkan indikator di atas, maka faktor 4 ini dapat diberi nama sebagai faktor spesifikasi dan penanganan material. 


\section{Faktor 5}

Faktor 5 terdiri dari 3 indikator yaitu sebagai berikut:

a. Indikator 30 (sisa pemotongan material tidak dapat dipakai lagi).

b. Indikator 31 (kesalahan pada saat memotong material).

c. Indikator 33 (sisa material karena proses pemakaian).

Berdasarkan indikator di atas, maka faktor 5 ini dapat diberi nama sebagai faktor residual.

7. Faktor 6

Faktor 6 terdiri dari 2 indikator yaitu sebagai berikut:

a. Indikator 29 (pengukuran di lapangan tidak akurat sehingga terjadi kelebihan volume).

b. Indikator 35 (buruknya pengontrolan material di proyek dan perencanaan manajemen terhadap sisa material).

Berdasarkan indikator di atas, maka faktor 6 ini dapat diberi nama sebagai faktor pengontrolan material.

Hasil PCA menunjukkan bahwa dari 35 indikator waste materials yang dievaluasi sebanyak 27 indikator yang dapat dikelompokkan menjadi 6 faktor dengan tingkat kemunculan sebesar 74,666\%. Dalam hal ini, ke 27 indikator waste materials tersebut telah timbul sementara sisa sebesar 25,334\% terdapat pada 8 indikator yang tidak timbul. Adapun 8 indikator waste materials yang tidak timbul adalah kesalahan dalam dokumen kontrak, ketidaklengkapan dokumen kontrak, kurang berkoordinasi dengan kontraktor dan kurang berpengetahuan tentang konstruksi, peralatan yang tidak berfungsi dengan baik, kecelakaan pekerja di lapangan, metode untuk menempatkan pondasi, informasi tipe dan ukuran material yang akan digunakan terlambat disampaikan kepada kontraktor, kehilangan akibat pencurian.

Faktor yang dominan menyebabkan timbulnya waste materials telah diidentifikasi melalui PCA, dalam hal ini varians tertinggi diperoleh pada faktor desain yaitu sebesar 36,922\%, oleh karena itu dari persepsi perusahaan kontraktor, faktor yang dominan menyebabkan timbulnya waste materials adalah faktor desain dengan kontribusi sebesar 36,922\%. Hasil penelitian ini selaras dengan 2 penelitian terdahulu yaitu faktor dominan yang menjadi penyebab adanya waste pada proyek gedung di Kota Surabaya adalah faktor perencanaan desain (Putra and Wiguna, 2019). Faktor yang sangat berpengaruh terhadap timbulnya limbah konstruksi di daerah Yogyakarta dan Kupang adalah perubahan desain (Hadut and Koesmargono, 2018).

Hasil penelitian ini terdapat beberapa perbedaan dengan 4 penelitian terdahulu. Faktor dominan yang menyebabkan waste konstruksi pada pelaksanaan pembangunan gedung adalah faktor material (Elizar, 2012). Faktor sisa material dominan yang terjadi selama pelaksanaan proyek konstruksi gedung di Provinsi Aceh adalah faktor residual (Julsena et al., 2018). Faktor-faktor yang paling sering menyebabkan terjadinya waste pada proyek gedung di wilayah Semarang adalah revisi dan distribusi gambar yang lambat serta terjadi perubahan desain (Hadiman et al., 2014). Faktor dominan timbulnya limbah konstruksi pada proyek pembangunan gedung di Bali adalah disebabkan oleh faktor pengetahuan dan keterampilan yang kurang (Widhiawati et al., 2019). 


\section{Kesimpulan dan Saran}

\subsection{Kesimpulan}

Faktor-faktor yang menyebabkan timbulnya waste materials dalam pelaksanaan proyek konstruksi gedung di Kota Banda Aceh terdapat 6 faktor yaitu faktor desain, pengadaan material, pelaksanaan, spesifikasi dan penanganan material, residual, dan pengontrolan material. Faktor yang dominan menyebabkan timbulnya waste materials dalam pelaksanaan proyek konstruksi gedung di Kota Banda Aceh adalah faktor desain dengan varians sebesar 36,922\%.

\subsection{Saran}

Disarankan kepada perusahaan kontraktor bidang gedung di Provinsi Aceh untuk menaruh perhatian besar terhadap faktor desain, pengadaan material, pelaksanaan, spesifikasi dan penanganan material, residual, dan pengontrolan material, agar waste materials dapat diminimalisir dan ditangani dengan baik. Disarankan kepada perusahaan kontraktor bidang gedung di Provinsi Aceh untuk mendukung program kota hijau (green city) di Kota Banda Aceh khususnya, dengan meminimalisir waste material sepanjang siklus pelaksanaan proyek konstruksi, sehingga mempunyai hasil pembangunan yang ramah terhadap lingkungan dan berkelanjutan (sustainable).

\section{Daftar Kepustakaan}

Bappeda Kota Banda Aceh, 2015. Green City (Kota Hijau).

Elizar, 2012. Kajian Faktor-faktor Penyebab Waste Konstruksi pada Pelaksanaan Pembangunan Gedung. Media Tek. Sipil XII, 41-46.

Hadiman, H., Hatmoko, J.U.D., Kistiani, F., 2014. Evaluasi Waste pada Proyek Gedung di Wilayah Semarang. J. Karya Tek. Sipil 3, 1120-1135.

Hadut, A.M., Koesmargono, 2018. Kajian Pengelolaan Sisa Material Konstruksi Terhadap Kontraktor di Yogyakarta dan Kupang, in: Prosiding Konferensi Nasional Pascasarjana Teknik Sipil (KTSP). pp. 73-82.

Hair, J., 2010. Multivariate Data Analysis. Pearson Education, New Jersey.

Jolliffe, I.T., 2013. Principal Component Analysis, Springer Series in Statistics. Springer New York.

Julsena, Abdullah, Rauzana, A., 2018. Faktor Sisa Material yang Mempengaruhi Biaya Pada Pelaksanaan Proyek Konstruksi Gedung di Provinsi Aceh. J. Arsip Rekayasa Sipil dan Perenc. 1, 148-155.

Putra, B.F., Wiguna, I.P.A., 2019. Analisis Faktor Penyebab Waste pada Proyek Konstruksi Gedung di Kota Surabaya dengan Metode Expected Monetary Value. ITS J. Civ. Eng. 34, 41-46.

Tarjo, 2019. Metode Penelitian Sistem 3x Baca. Deepublish, Yogyakarta.

Widhiawati, I.A.R., Astana, N.Y., Indrayani, N.L.A., 2019. Kajian Pengelolaan Limbah Konstruksi pada Proyek Pembangunan Gedung di Bali. Ilm. Tek. Sipil 23, 55-61. 